\title{
Amoebic chronic appendicitis: a rare entity
}

\section{Krishna $\mathrm{M}^{1}$}

${ }^{1}$ UP University of Medical Sciences, Saifai Etawah, Uttar Pradesh, India

\author{
Keywords: \\ Appendicitis; \\ Entamoeba histolytica; \\ Amoebic
}

\author{
ABSTRACT \\ Rarely intestinal parasites can cause acute appendicitis. Amoebic appendicitis is rare and infection \\ with Entamoeba Histolytica usually develops as an extension of caecal infection. I report a rare case of \\ amoebic chronic appendicitis diagnosed on histopathology examination. It mimics the features of acute \\ appendicitis but may not always be responsible for acute appendicitis
}

\section{INTRODUCTION}

Appendix is usually 6-9 $\mathrm{cm}$ in length however may range in length from 1-30 cm. The inflammation of appendix is generally secondary to obstruction of the lumen of the appendix. The common causes of acute appendicitis are faecal stasis, Fecoliths and lymphoid hyperplasia. Rarely intestinal parasites can cause acute appendicitis. A pathogenic amoeba is geographically the most widely distributed of the protozoal diseases. Amoebiasis is an infection due to Entamoeba histolytica (E. histolytica), which is ingested with contaminated food. The lesions produced by $\mathrm{E}$. histolytica in the colonic mucosa involve principally the caecum, ascending colon and rectosigmoid. Amoebic chronic appendicitis is rare and infection with E.H usually develops as an extension of caecal infection. ${ }^{1}$ Here, we report a rare case of chronic appendicitis, which on examination reveals colonies of E. histolytica trophozoites in the lumen with mucosal ulceration and evidence of chronic appendicitis.

\section{Correspondence:}

Dr. Mani Krishna, MBBS, MD

Associate Professor, Department of Pathology

UP University of medical sciences, Saifai Etawah 206301,

Uttar Pradesh, India.

E-mail:drmanikrishna@gmail.com

\section{CASE REPORT}

A 22 year old male was attended to the surgery OPD, presented with abdominal pain. Here he is diagnosed as appendicular lump. He got relief by conservative treatment and then discharge. After some days he came with abdominal pain since two day which was insidious in onset, starting from mild grade progressive in nature, mainly in right lumber region and up to umbilicus, associated with vomiting. On physical examination no organomegaly was found. Haematological examination revealed $\mathrm{Hb} 14.8$ gm /dl, TLC 10.8x103/UL, DLC polymorph (62.3\%), lymphocyte (18\%) and eosinophil $19.7 \%$ with platelet count $1.42 \mathrm{lakh} / \mathrm{Cu} \mathrm{mm}$. Serum HIV and HBsAg were negative. The patient did not give any history of passage of parasite in stool. The chest radiograph did not reveal any abnormality. USG revealed appendicitis. Provisional diagnosis was recurrent appendicitis. He underwent laparoscopic appendectomy. During procedure appendix was retrocaecal and adhere to caecum, adhesionolysis done and appendix send for histopathological examination (HPE). Specimen of the appendix was received in $10 \%$ buffered formalin. Grossly the $6 \mathrm{~cm}$ appendix was congested and swollen, on cut section lumen was dilated and filled with purulent. The 


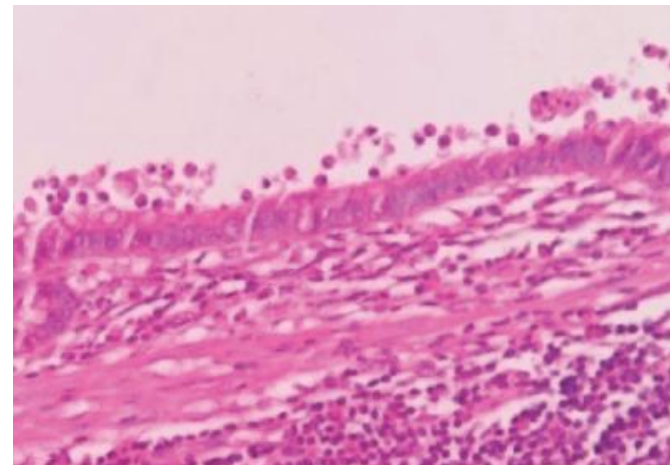

Figure 1: Photomicrograph showing trophozoites of E. Histolytica in the surface of mucosa of the appendix(HE stain X50).

sections were routinely processed, paraffine-embedded and 4-micron-thick sections were prepared. Microscopically, few trophozite of Entameba histolytica near or invade to the mucosa were identified in the dilated lumen.(fig. 1 and 2) Focal exudation was found. The wall of the appendix showed chronic inflammatory infiltrates including eosinophil. Periodic acid Schiff (PAS) stain revealed better morphology of the trophozoites. (fig.2,inset) Histopathology diagnosis, amoebic chronic appendicitis was made.

\section{DISCUSSION}

Appendisectomy is the most commonly performed emergency surgery worldwide. ${ }^{2}$ Tubular structure and a narrow lumen makes it more prone to closed loop obstruction. Parasitic infection must be kept in the differential diagnosis of appendicitis with high index of suspicion in patients with doubtful clinical findings, normal white cell count and increased eosinophils, especially if right iliac fossa pain is recurrent. In most instances stool examinations are not seriously considered as part of the investigation in cases diagnosed as acute, subacute or chronic appendicitis. In this study, no evidence of stool examination was present. There was no associated diarrhoea in the clinical presentation. Appendicitis related to E.histolytica is quite rare. The literature contains only a few reports of amebic appendicitis. ${ }^{3-5}$ Exact incidence of this unusual presentation of parasitic disease is not well known. Before operation, routine laboratory tests are generally not useful but leukocytosis and anaemia may be seen and can be correlate. Even after thorough clinical, radiological and haematological evaluation are done. Elimination of appendicitis in differential diagnosis of these patients cannot be possible all the time. In most of the case, parasites in the appendix lumen do not invade the mucosa or the submucosa or cause acute inflammation. In this study amoebic chronic appendicitis, parasites invade the mucosa or cause chronic inflammation. ${ }^{5}$ This report highlight chronic appendicitis of amoebic origin. Appendicular amoebiasis can give the clinical features of acute appendicitis. Appropriate medication should be initiated to prevent from systemic effects of the disease

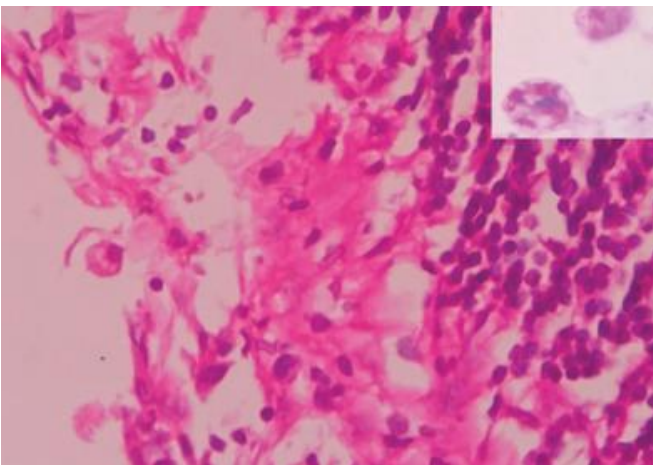

Figure 2: Photomicrograph showing trophozoites of E. Histolytica in the ulcerated mucosa of the appendix $(H \& E, 40 x)$.

or prevent post surgery septic complication. ${ }^{6}$ Therefore all appendicectomy specimens should be histopathological examined and pathologists should keep in their mind the rare possibility of parasitic infection.

\section{CONCLUSION}

However, the E.histolytica is rare cause of acute appendicitis but they must be considered as a possible suspect. Treatment of choice is appendectomy but antimicrobials treatment should be given before the patient is discharged from the wards to avoid complication.

\section{REFERENCES}

1. Nadler S, Cappell MS, Bhatt B, Matano S, Kure K. Appendiceal infection by Entamoeba histolytica and Strongiloides stercoralis presenting as acute appendicitis. Dig Dis Sci 1990;35:603-8. Crossref

2. Humes DJ, Simpson J. Acute appendicitis. BMJ 2006; 333:530-4. Crossref

3. Hakan Yabanoglu, Huseyin Ozgur Aytac, Emin Turk, Erdal Karagul le, Kenan Caliskan, Sedat Belli, Fazilet kayase lcuk, Mehmet Akin Tarim. Parasitic infections of appendix as a cause of appendectomy in adult patients. Turkiye Parazitol Derg 2014;38:12-6 Crossref

4. M.A. Hegazi, T. A. Patel. Acute amoebic appendicitis: Case reports and Review of parasitic appendicitis. Journal of the Pediatric Infectious Diseases Society 2013;2:80 Crossref

5. Naorem Gopendro Singh, A.A.S. Rifat Mannan, Mirza Kahvic. Acute amoebic appendicitis: Report of a rare case. Indian Journal of Pathology an Microbiology 2010;53:767-68. Crossref

6. Kleitsch, W.P. and L.D. Cherry: The Surgerical Importance of Amebiasis. Mil. Surgeon 1949;105:458. Crossref 